\title{
SISTEM PENGELUARAN DAN PEMASUKAN STOK BARANG PADA PT MULIA JAYA TEXTILE
}

\author{
Yohana Lavania' $^{1}$, Imam Himawan² ${ }^{2}$ Yuni Wibawanti ${ }^{3}$ \\ 1,2,3 Universitas Indraprasta PGRI \\ Jl. Raya Tengah No.80, Kel Gedong, Kec. Pasar Rebo, Jakarta Timur \\ 11avaniayohana@gmail.com, ${ }^{2}$ imamhimawann@gmail.com, ${ }^{3}$ yuniwib206@gmail.com
}

\begin{abstract}
ABSTRAK
Sistem informasi pengeluaran dan pemasukan stok barang merupakan komponen yang penting di suatu perusahaan untuk mengetahui stok barang yang dimiliki sehingga mempermudah dalam mengoperasional perusahaan. Permasalahan yang terjadi dalam stok barang adalah pengolahan data keseluruhan barang dan pembuatan laporan. Hal ini mendorong peneliti untuk membuatkan sistem yang akan mempermudah dalam pengolahan data stok barang dan pembuatan report atau laporan. Pada penelitian peneliti menggunakan metode grounded research. Penelitian ini menyimpulkan bahwa dalam pengolahan data pemasukan dan pengeluaran barang pada PT. Mulia Jaya Textile masih melakukan pendataan manual menggunakan buku besar, untuk mengatasi permasalahan ini peneliti melakukan pengembangan sistem informasi pengeluaran dan pemasukan stok barang menggunakan aplikasi yang diharapkan memudahkan dalam pengolahan data stok barang yang akurat dan efisien.
\end{abstract}

Kata Kunci: Sistem, Stok, Textile, Java,

\begin{abstract}
The information system of expenditure and entry of stock of goods is an important component in a company to find out the stock of goods owned so as to facilitate the operation of the company. The problem that occurs in the stock of goods is the overall data processing of goods and report generation. This encourages researchers to develop a system to make it easier to process stock data and make reports. In this study using the grounded research method. This study concludes that in processing data entry and exit of goods at PT. Mulia Jaya Textile is still doing manual data collection using a ledger, to overcome this problem, researchers are developing an information system for spending and entering stock items using an application that is expected to facilitate more accurate and efficient stock data processing.
\end{abstract}

Key Word: Information System, Stock, Textile, Java, Netbeans.

\section{PENDAHULUAN}

Perkembangan kehidupan manusia pada zaman ini sangat canggih karena ditunjang dengan berbagai aspek yang diantaranya ialah teknologi, ekonomi, hiburan dan lain-lain, setiap orang bercengkerama dalam bidangnya untuk terus mengembangkan diri dalam mengikuti perkembangan zaman agar terus bersaing dalam kehidupan (Sudarmaji et al., 2021). Manusia maupun perusahaan harus melakukan suatu tindakan yang sesuai agar dapat bersaing. Tindakan yang diambil oleh manusia ataupun perusahaan memerlukan adanya inovasi informasi yang memadai. Untuk tindakan yang dilakukan dapat sesuai dengan kebutuhan masing-masing. Informasi dibutuhkan untuk mengurangi hal-hal yang tidak pasti di dalam proses yang memerlukan pengambilan keputusan dalam suatu situasi dan keadaan. Kualitas dari suatu sistem informasi tergantung pada tiga hal pokok yang sangat penting yaitu tepat waktu, akurat dan relevan.

PT. Mulia Jaya Textile bergerak dibidang tekstil, menjual bahan kain yang di impor dari luar negeri dan lokal (dalam negeri). PT. Mulia Jaya Tekstil berdiri sejak 2003 dan beralamat di Jalan Ciledug Raya Nomor 8 RT.08, RW. 5, Ulujami, Pesanggrahan, Jakarta. PT. Mulia Jaya Tekstil memiliki 116 karyawan dan memiliki 1 cabang perusahaan di Tanah Abang, dipercaya perusahaan ini banyak dijadikan pilihan oleh banyak pelanggan saat ini, tetapi pengolahan data seperti pengeluaran dan pemasukan barang di perusahaan ini masih belum ditunjang oleh fasilitas yang baik.

Dalam melakukan pendistribusian barang kepada costumer sering terjadi kesalahan informasi dan laporan mengenai hal-hal yang berkaitan dengan pengeluaran dan pemasukan 
barang. Pengolahan data dilakukan karyawan saat ini masih memiliki sedikit kekurangan, yang diantaranya terlambat dalam menghasilkan informasi atau laporan, juga terjadinya kesalahan data yang berakibat informasi yang telah dihasilkan tidak sesuai realitas dengan yang terjadi. Salah satu faktor yang terjadinya beberapa kesalahan pengolahan data-data adalah karena untuk semua proses pengolahan data-data seperti data-data barang, data pembeli, stok barang, harga jual dan laporan laba menggunakan data-data yang terpisah akhirnya seringkali terjadi perbedaan data. Berhubungan dengan hal diatas maka penulis mengambil judul penulisan mengenai: "Sistem Informasi Pengeluaran dan Pemasukan Stok Barang Pada PT Mulia Jaya Textile Berbasis Java Desktop."

\section{METODE PENELITIAN}

Metode penelitian dasarnya merupakan cara ilmiah untuk mendapatkan data tujuan dan kegunaan tertentu (Sugiono, 2014). Sedangkan menurut (Ramadhan et al., 2020) metode penelitian adalah cara yang digunakan oleh peneliti dalam mengumpulkan data penelitian. Research and Development (R \& D) merupakan an industry-based development model, yang berpandangan bahwa temuan penelitian digunakan untuk mengembangkan produk baru (Surahman et al., 2020). Menurut (Sugiono, 2017) Pengumpulan data adalah alat bantu yang dipilih oleh peneliti dan digunakan dalam kegiatannya mengumpulkan data agar kegiatan tersebut menjadi sistematis dan dipermudah olehnya.

Metode pengumpulan data merupakan aspek yang berperan penting dalam kelancaran dan keberhasilan perancangan sistem, data yang diperlukan berupa data pengeluaran untuk rancang bangun sistem pengeluaran barang pada PT. Mulia Jaya Textile. Metode pengumpulan data Research and Development (R \& D) yang dilakukan penulis untuk mendapatkan data-data dan informasi untuk mendukung penyempurnaan hasil dari penelitian ini. Menurut (Rahmaningtyas et al., 2018) Sistem informasi akademik saat ini telah manjadi bagian yang penting dalam menyambut era modern saat ini, dimana data akademik merupakan pokok penting dalam suatu kegiatan akademik. Menurut (Putra \&
Vadriasmi, 2020) Penelitian dilaksanakan dengan metode survey dengan pendekatan kombinasi dari kuantitaf dan kualitatif, untuk mendapatkan gambaran secara objektif tentang manajemen bencana alam dalam persepsi responden.

\section{HASIL DAN PEMBAHASAN}

Dari hasil penelitian yang di lakukan maka penulis dapat menganalisis permasalahan yang ada pada sistem pemasukan dan pengeluaran stok pada PT. Mulia Jaya yaitu:

1. Masih seringnya terjadi kehilangan berkas yang mengakibatkan keterlambatan pembuatan laporan kepada pemimpin.

2. Masih menggunakan pembukuan manual sebagai tempat menyimpan data dan mengolah laporan sehingga data sering terduplikasi satu sama lain dan sering terjadinya kehilangan berkas mengakibatkan keterlambatan dalam bekerja.

\section{Alternatif penyelesaian masalah}

1. Perancangan database untuk sistem pemasukan dan pengeluaran stok sehingga penyimpanan data tidak menggunakan manual atau media kertas lagi.

2. Membuat sistem inventori gudang material yang memudahkan peneliti dalam menyusun laporan serta menghasilkan hasil laporan yang tepat dan akurat.

Menurut (Pamungkas, 2017) Sistem Informasi berperan sebagai sistem karena mempunyai ruang lingkup yang relatif lebih luas dan lebih kompleks. Sedangkan sistem basis data merupakan subsistem karena menjadi bagian dan berada di dalam Sistem Informasi Sistem basis data adalah sistem informasi yang mengintegrasikan kumpulan dari data yang saling berhubungan satu dengan yang lain dan membuatnya tersedia untuk beberapa aplikasi yang bermacammacam di dalam suatu organisasi Keberadaan sistem basis data di dalam Sistem Informasi adalah mutlak. Sistem Informasi tidak akan terwujud tanpa melibatkan basis data.

Diagram Alir Data adalah suatu diagram yang memperlihatkan aliran data-data dari objek sumber melewati suatu proses yang kemudian 
di ubah menjadi nilai keluaran maupun disimpan dalam tempat penyimpanan sementara (Wikipedia.org, 2019). Membuat daftar tentang kegiatan yang digunakan untuk menentukan bermacam entitas eksternal, aliran data, proses-proses, dan penyimpanan data.

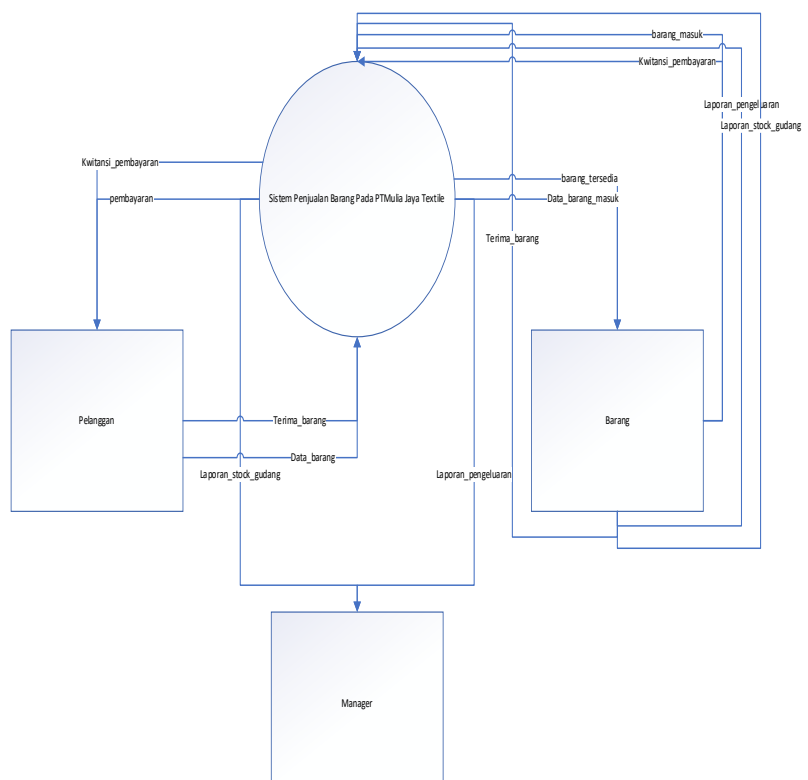

Gambar 1. Diagram Konteks Sistem yang Diusulkan.

ERD adalah bagian yang menunjukkan hubungan antara entity yang ada dalam sistem (Winaryatin, 2016).

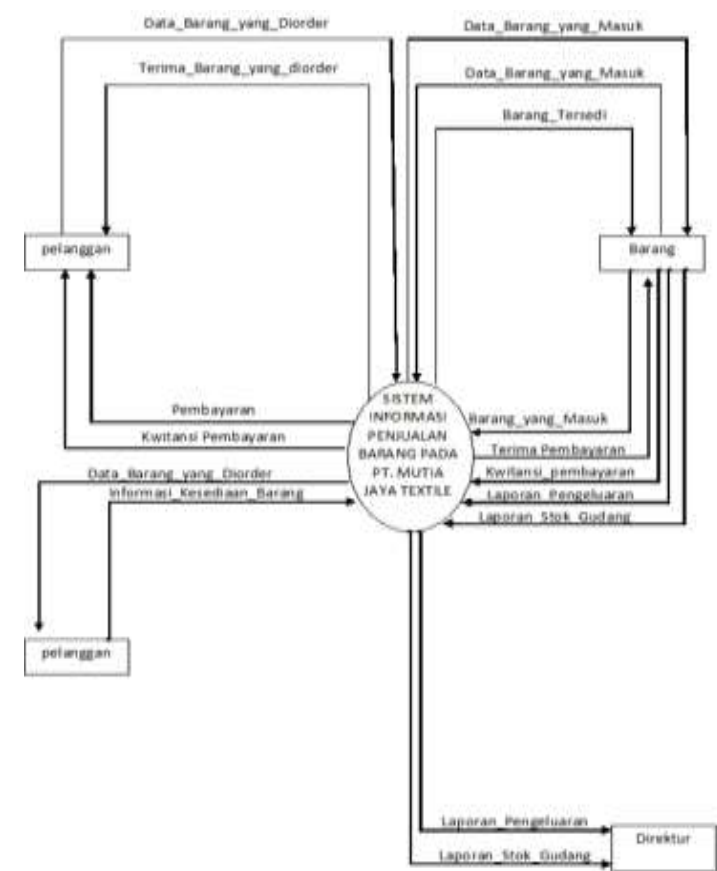

Gambar 2. Diagram Konteks Sistem Berjalan

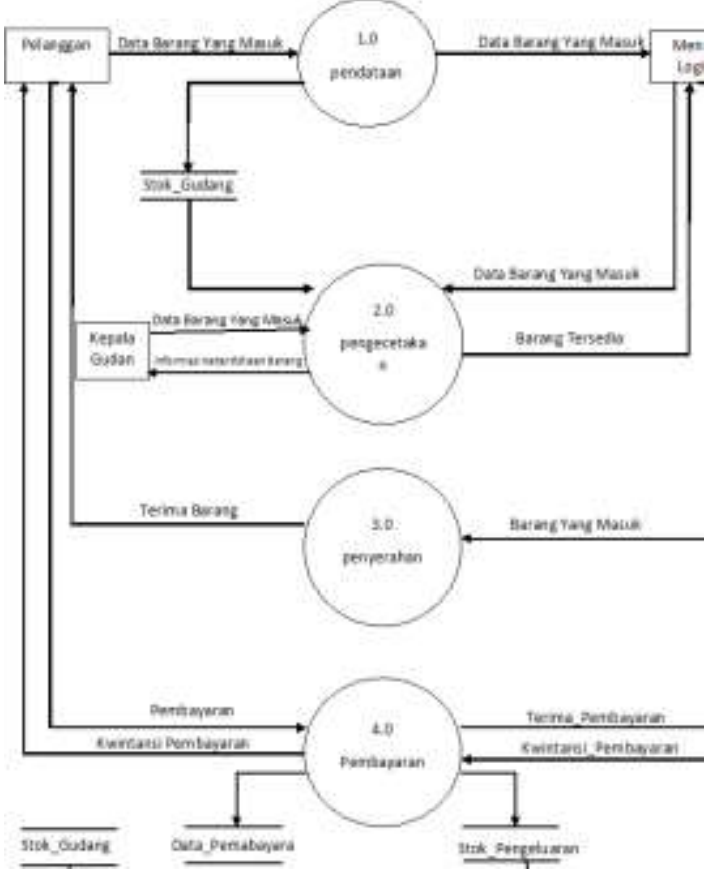

Gambar 3. Diagram Nol Sistem Berjalan

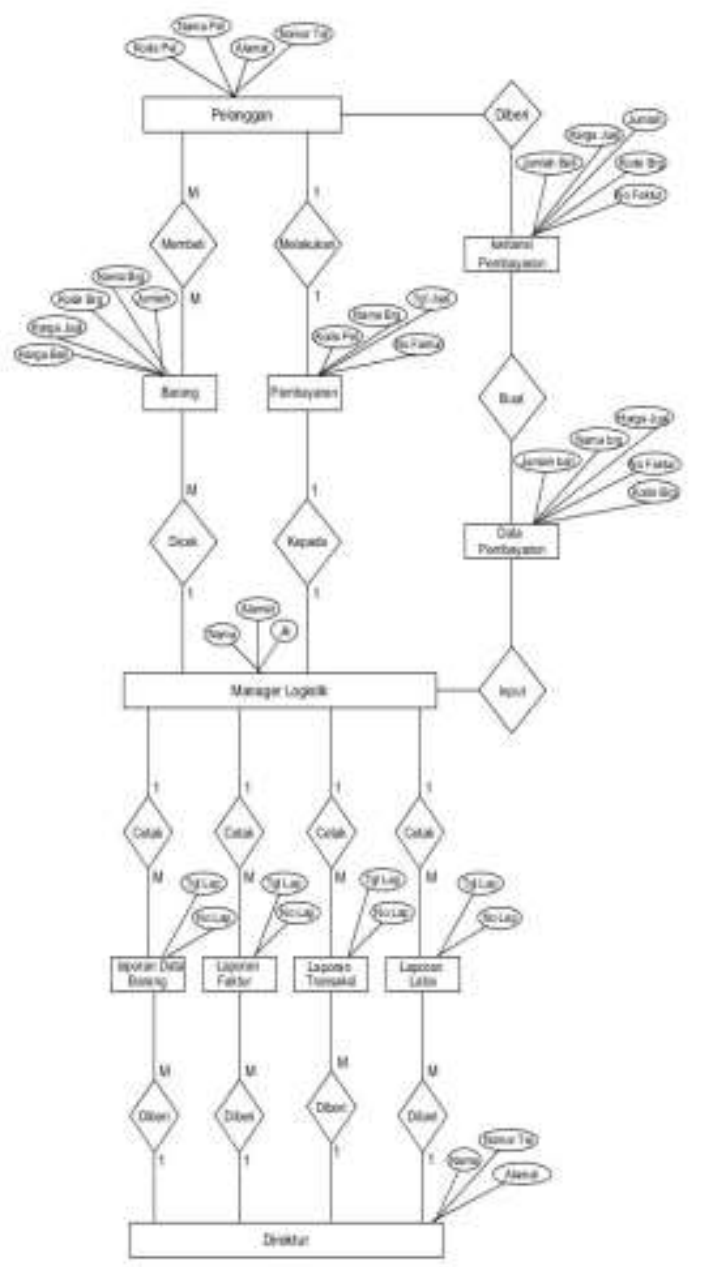

Gambar 4. Entity Relationship Diagram (ERD) 


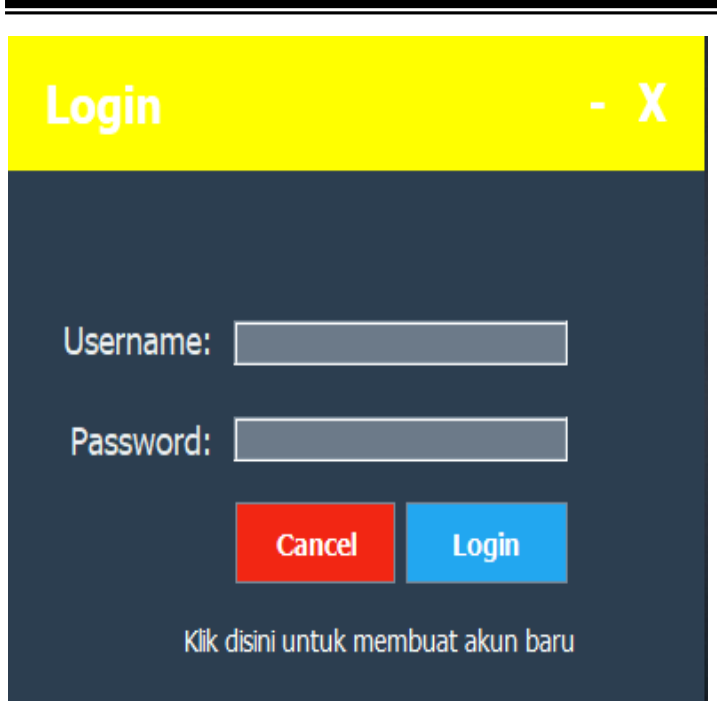

Gambar 5. Tampilan Layar Login

Tampilan menu login muncul saat pengoperasian program sistem administrasi diisi oleh bagian admin. Jika nama pengguna dan kata sandi sesuai akan masuk ke tampilan menu utama.

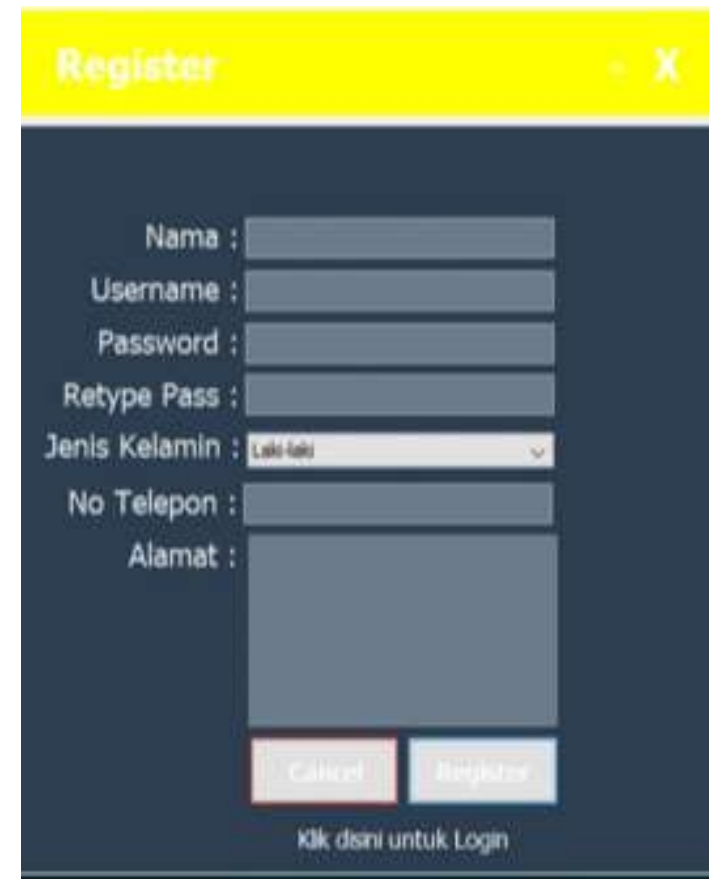

Gambar 6. Tampilan Layar Registrasi

Tampilan registrasi merupakan form untuk, memasukkan data akun baru sehingga akun baru bisa mengakses aplikasi ini.

\section{Dre}

Gambar 7. Tampilan Layar Menu Utama

Tampilan menu utama terdapat beberapa menu yang akan di tampilkan pada saat aplikasi pertama kali dijalankan. Pada layar menu (utama) tersedia menu bar yang terdiri dari beberapa data menu yang digunakan untuk melakukan memanipulasi data master seperti data pelanggan, satuan, supplier, kategori, barang, pengeluaran barang, pemasukan barang, stock, laporan, keluar.

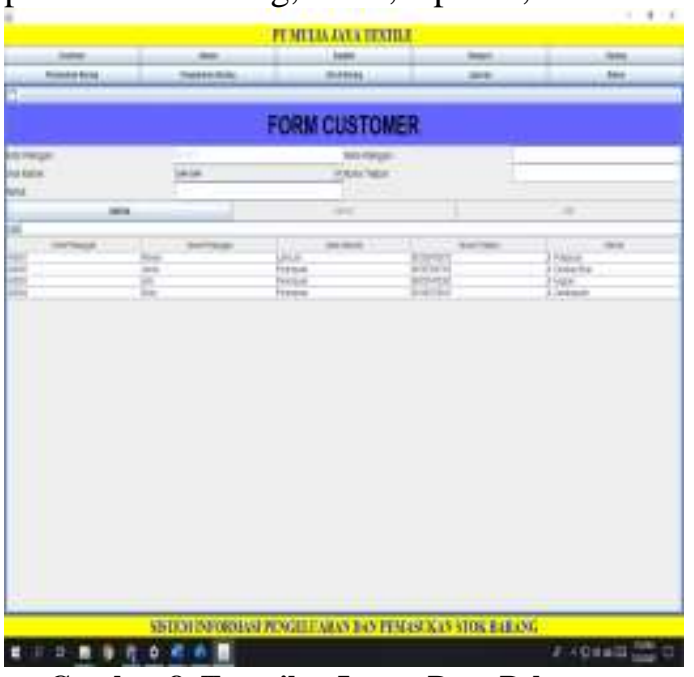

Gambar 8. Tampilan Layar Data Pelanggan

Tampilan layar pelanggan merupakan tampilan data untuk memasukkan data pelanggan.

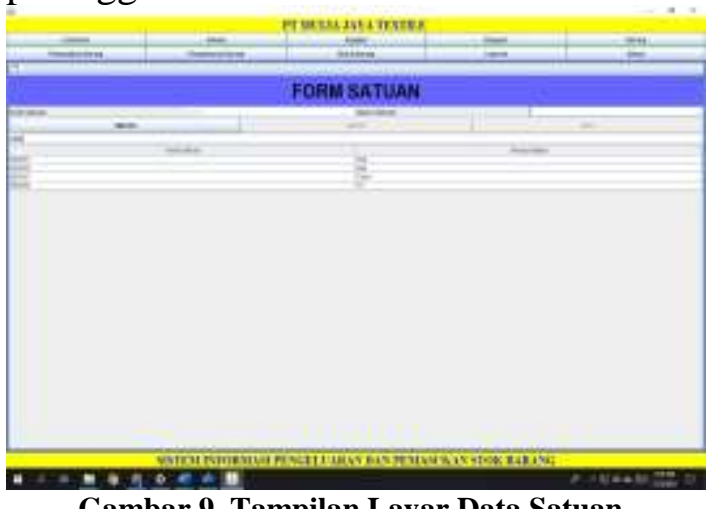

Gambar 9. Tampilan Layar Data Satuan 
Tampilan layar data satuan merupakan tampilan untuk memasukkan data satuan.

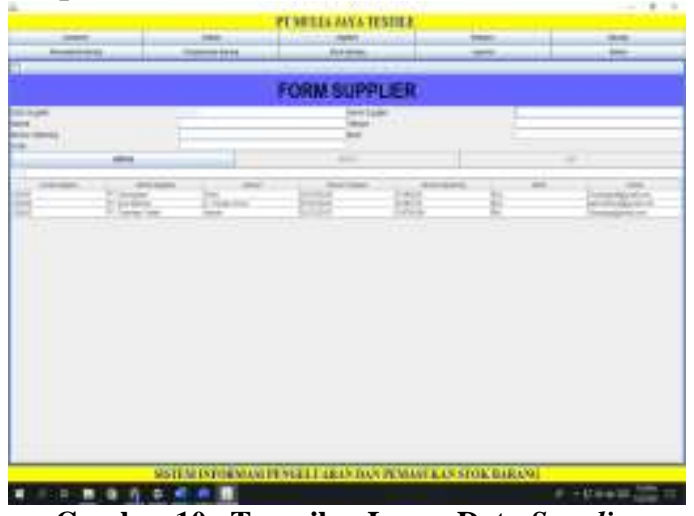

Gambar 10. Tampilan Layar Data Supplier

Tampilan layar data supplier merupakan tampilan untuk memasukan data supplier.

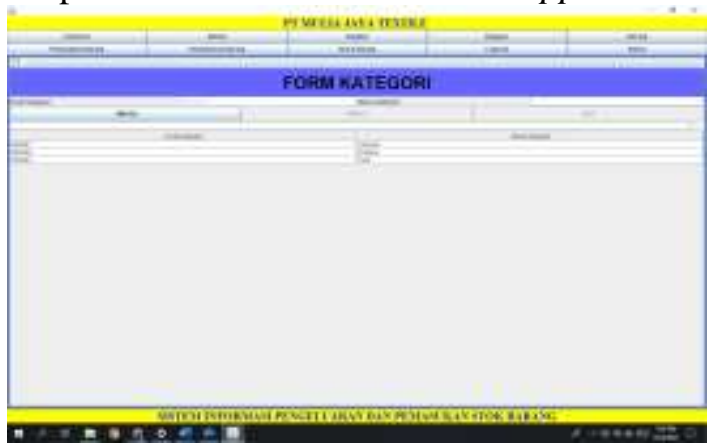

Gambar 11. Tampilan Layar Data Kategori

Tampilan layar data kategori merupakan tampilan untuk memasukkan kategori barang.

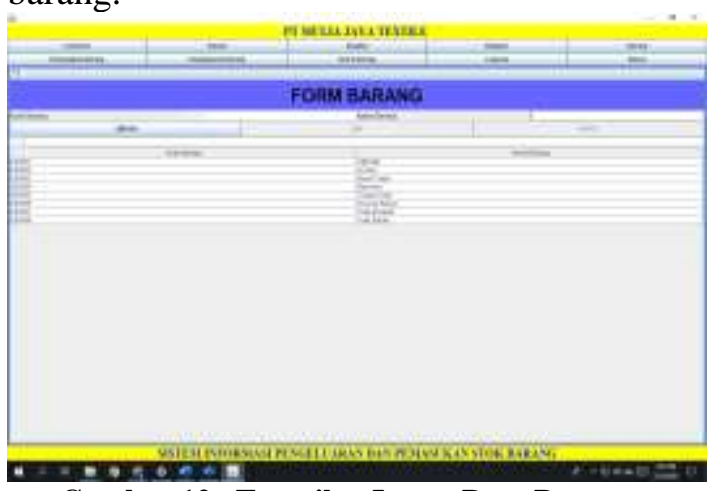

Gambar 12. Tampilan Layar Data Barang

Tampilan layar data barang merupakan tampilan untuk memasukkan data barang.

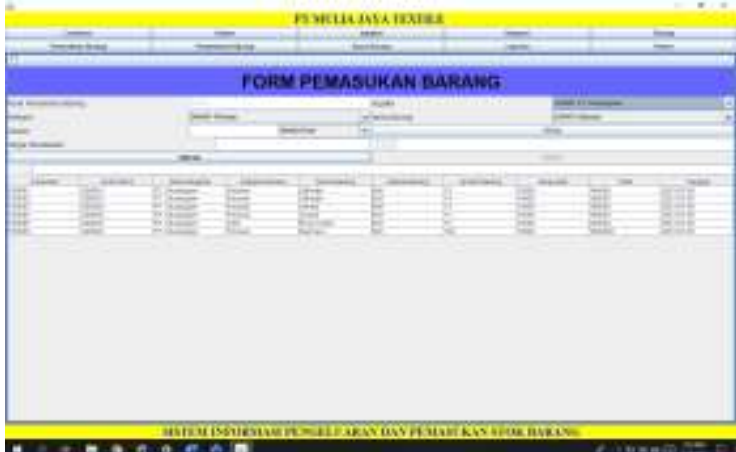

Gambar 13. Tampilan Layar Data Pemasukan Barang

Tampilan data pemasukan barang merupakan tampilan untuk menampilkan data barang dan entitas lainnya untuk di tampilkan dan pengeluaran barang.

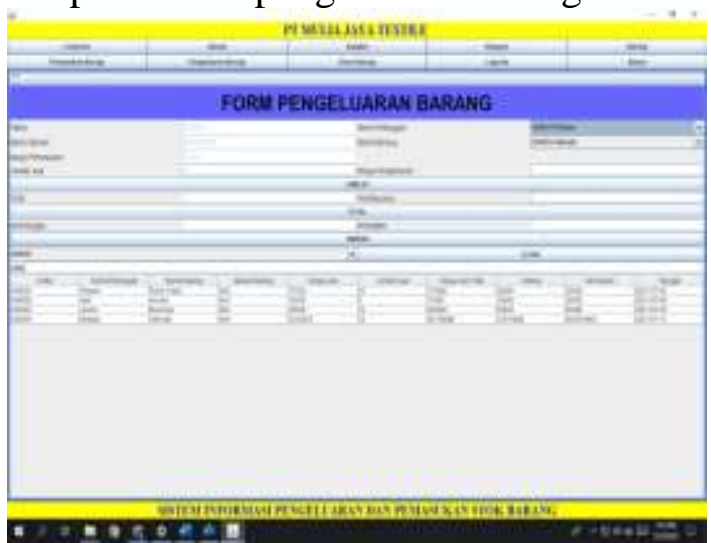

Gambar 14. Tampilan Layar Data Pengeluaran Barang

Tampilan layar data pengeluaran barang merupakan tampilan yang menampilkan data input dan transaksi pengeluaran barang.

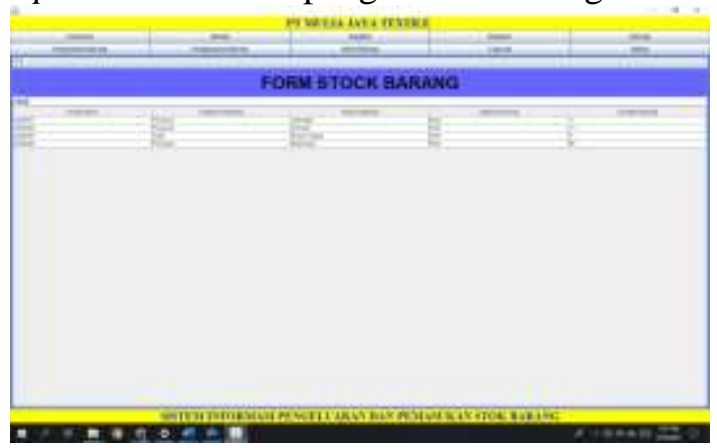

Gambar 15. Tampilan Layar Data Stock Barang

Tampilan layar data stock barang merupakan tampilan dari pengeluaran barang dan pemasukan barang. 


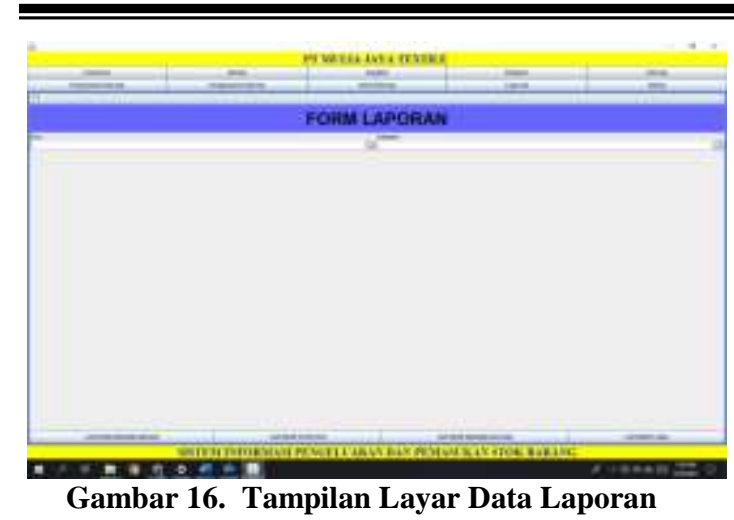

Tampilan layar data laporan merupakan tampilan untuk mencetak entitas barang. Tampilan Layar Laporan Barang Masuk

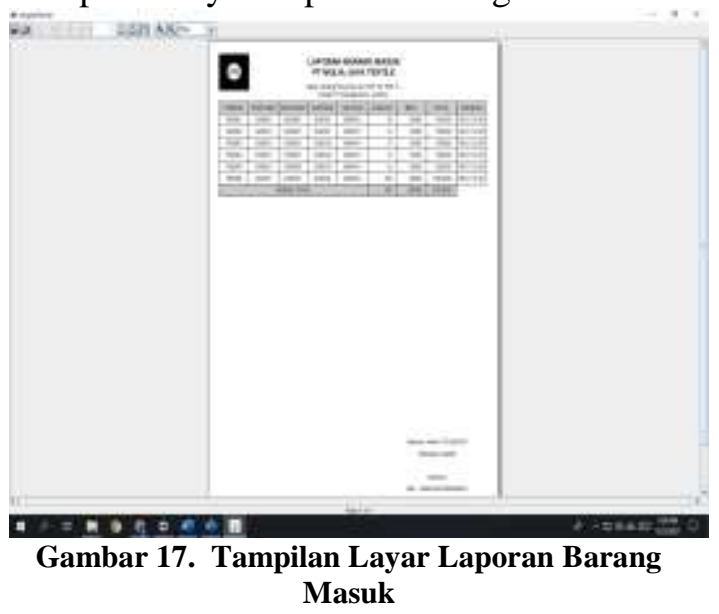

Tampilan laporan data barang masuk merupakan tampilan dari laporan barang masuk.

\section{SIMPULAN DAN SARAN}

Dengan dibuatnya sistem informasi pengeluaran dan pemasukan stok barang pada PT. Mulia Jaya Textile ini dimaksudkan untuk dapat menangani pekerjaan administrasi dalam pendataan data Pengeluaran barang secara cepat, akurat dan mempermudah dalam penggunaan untuk pengolahan data Pengeluaran barang yang tidak lagi dilakukan secara manual tetapi menggunakan media berupa komputer.

Aplikasi sistem informasi Pengeluaran barang ini membawa dampak yang baik terhadap PT. Mulia Jaya Textile, karena efektivitas dan efisien dapat tercapai dalam hal pengolahan data Pengeluaran barang yang terkomputerisasi dan terintegrasi secara baik. Aplikasi sistem informasi Pengeluaran barang yang telah dibuat dapat meningkatkan pengawasan terhadap kegiatan yang lebih mudah, karena adanya laporan kegiatan yang tepat.

Sejalan Dengan sistem usulan penulis buat, maka tercapainya tujuan dan data sasaran yang diharapkan, maka penulis dapat memberi saran: Sistem informasi pengeluaran barang yang dibuat masih harus diadakan evaluasi secara berkala agar aplikasi dapat dikembangkan dan dapat menjadi lebih baik untuk digunakan dengan penelitian atau analisa yang lebih spesifik.

Melakukan pemeliharaan data dengan backup data secara berkala untuk mengantisipasi segala kemungkinan yang dapat terjadi terhadap kinerja sistem. Perlunya diadakan pengarahan atau pelatihan terhadap staf yang bertanggung jawab atas kegiatan pengolahan data gudang agar penggunaan aplikasi sistem informasi Pengeluaran barang ini dapat dirasakan secara optimal. Dalam hal tampilan aplikasi sistem informasi pengeluaran barang ini masih sangat sederhana, dan masih membutuhkan penambahan desain atau fitur yang sesuai dengan kebutuhan dalam kegiatan di perusahaan.

\section{UCAPAN TERIMAKASIH}

Dengan memanjatkan puji syukur ke hadirat Tuhan Yang Maha Esa telah melimpahkan rahman dan karuniaNya kepada peneliti sehingga penulis mampu menyelesaikan Skripsi/tugas akhir, guna melengkapi persyaratan untuk kelulusan Strata Satu (S1) jurusan Informatika pada Universitas Indraprasta PGRI. Penulis juga mengucapkan terimakasih untuk dukungan dan bantuan yang di berikan dari keluarga, dosen, teman - teman.

\section{DAFTAR PUSTAKA}

Pamungkas, C. A. (2017). Pengantar dan Implementasi Basis Data. In Pengantar dan Implementasi Basis Data (p. 68).

Putra, D. M., \& Vadriasmi, D. (2020). Analisis Penerapan Sistem Informasi Manajemen Rumah Sakit (SIMRS) di TPPRJ Menggunakan Metode UTAUT di RS Tk.III dr. Reksodiwiryo Padang. Administration \& Health Information of Journal, Vol 1(1).

Rahmaningtyas, Y., Diartono, D., \& Kom, S. (2018). Aplikasi Mobile Sistem 
Informasi Akademik Pada Sekolah Dasar Negeri Sendangmulyo 02 Semarang. In Information Technology and Telematics (Vol. 8, Issue Vol 8 No 1 (2018)).

Ramadhan, F., Saputra, S., \& Fitriansyah, A. (2020). Sistem Penyewaan Alat-alat Selam Berbasis Website pada Fisheries Diving Club (FDC) Universitas Hasanuddin. Jurnal Riset Dan Aplikasi Mahasiswa Informatika (JRAMI), 1(02). https://doi.org/10.30998/jrami.v1i02.26 1

Sudarmaji, H., Prasojo, G. L., Rubiono, G., \& Arif, R. (2021). SKYHAWK : Jurnal Aviasi Indonesia Pendidikan Vokasi Aviasi: Peluang dan Tantangan. SKYHAWK: Jurnal Aviasi Indonesia, l(1).

Sugiono. (2017). Instrumen penelitian metopen. Metodologi Penelitian Kuantitatif.

Sugiono, P. D. (2014). Metode penelitian pendidikan pendekatan kuantitatif.pdf. In Metode Penelitian Pendidikan Pendekatan Kuantitatif, Kualitatif Dan $R \& D$.

Surahman, E., Satrio, A., \& Sofyan, H. (2020). Kajian Teori Dalam Penelitian. JKTP: Jurnal Kajian Teknologi Pendidikan, 3(1), 49-58. https://doi.org/10.17977/um038v3i1201 9p049

Wikipedia.org. (2019). Diagram Alir Data. Id.Wikipedia.Org.

Winaryatin, E. R. (2018. (2016). Landasan Teori. In Landasanteori.Com (Vol. 5, Issue 2012). http://www.landasanteori.com/2015/09/ pengertian-kreativitas-definisiaspek.html 